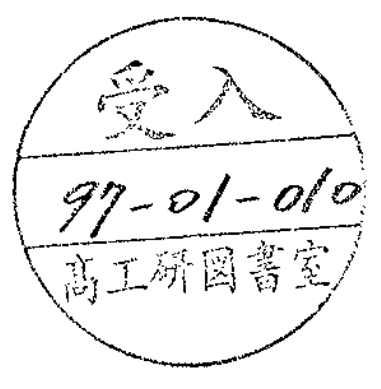

CERN-PPE/96-147

26 July 1996

\title{
ON THE SCINTILLATION RESPONSE OF NaI(TI)-CRYSTALS
}

\author{
H. Leutz and C. D'Ambrosio \\ CERN, Geneva, Switzerland
}

\begin{abstract}
Several articles are reviewed on the scintillation response of $\mathrm{NaI}(\mathrm{Tl})$. Those publications which report on results obtained with radioactive sources either dispersed throughout the $\mathrm{NaI}(\mathrm{Tl})$-lattice or located inside the wells of $\mathrm{NaI}(\mathrm{Tl})$-crystals, match within $\pm 0.9 \%$ standard deviation a linear scintillation response between $3 \mathrm{MeV}$ and $3 \mathrm{keV}$. Several authors who placed their sources outside the crystals, measured non linear responses of $\mathrm{NaI}(\mathrm{Tl})$ with up to $\pm 5.3 \%$ standard deviations between $700 \mathrm{keV}$ and $4.5 \mathrm{keV}$. The presented analysis suggests that the observed non-linearity is not an intrinsic effect of $\mathrm{NaI}(\mathrm{Tl})$, but could be caused, at least partly, by effects occuring at the radiation entrance surfaces of the crystals.
\end{abstract}




\section{INTRODUCTION}

In a recent paper [1], P. Dorenbos et al. reviewed the scintillation response and the energy resolution of scintillation crystals. In the case of $\mathrm{NaI}(\mathrm{Tl})$, they based their conclusions only on publications [2-9] which report a non-linear scintillation response, particularly around the iodine $\mathrm{K}$ - and $\mathrm{L}$-absorption edges and an increase of light emission between about $1 \mathrm{MeV}$ and $0.05 \mathrm{MeV}$. They did not quote any papers which explicitly report a linear scintillation response of $\mathrm{NaI}(\mathrm{Tl})$ (e.g. [10-12]).

To demonstrate that the scintillation response of $\mathrm{NaI}(\mathrm{Tl})$ can still be disputed, we have analyzed some further publications [13-16], where the radiactive sources have been either uniformly dispersed throughout the NaI(Tl)-lattice (internal source technique) or have been located inside the wells of $\mathrm{NaI}(\mathrm{Tl})$-crystals to achieve an almost uniform detection efficiency over the entire solid angle. The mostly applied arrangements [2-11] placed their gamma (X-ray) or electron sources outside the $\mathrm{NaI}(\mathrm{Tl})$-crystals striking their flat surfaces with collimated or uncollimated beams.

\section{ANALYSIS}

The scintillation efficiency defined as the light yield per unit absorbed energy is plotted versus excitation energy in fig. 1. The four dashed curves are taken from D. Engelkemeir (fig. 2 in reference [3]), D. W. Aitken et al. (fig. 1 in reference [7]), W. Hink (fig. 4 in reference [5]) and B. D. Rooney and J. D. Valentine (fig. 3 in reference [17]). The curve of Engelkemeir [3] is normalized to an average value of unity, which results in a change from the original value of 1.0 to 0.9 scintillation efficiency at $662 \mathrm{keV}$ energy. The curve of Aitken et al. [7] and that of Rooney and Valentine [17], who measured the $\mathrm{NaI}(\mathrm{Tl})$-light yield of Compton electrons in coincidence with the escaping Compton-gammas at different angles between the collimated $\gamma$-beam and the position of a highly purified Ge-detector (HPGe), are normalized to that of Engelkemeir at $80 \mathrm{keV}$ 
energy. The curve of Hink [5] is copied from his original figure. The individual scintillation efficiencies displayed in fig. 1 are taken from different publications [12-16]. They need some explanations :

S. Buhl et al. [12] transmitted within their experimental arrangement (fig. 1 in reference [12]) $\mathrm{K}$ X-rays from $\mathrm{Br}, \mathrm{Mo}, \mathrm{Ag}, \mathrm{I}, \mathrm{Ba}, \mathrm{Ce}, \mathrm{Nd}, \mathrm{Gd}$, Ta, and $\mathrm{Au}$ targets through an air filled ionisation chamber and absorbed them in the well $(2.7 \mathrm{~mm}$ diameter, $4 \mathrm{~mm}$ depth) of a $\mathrm{NaI}(\mathrm{Tl})$-crystal (13 $\mathrm{mm}$ diameter, $8.5 \mathrm{~mm}$ height). The fluorescent intensity F measured via the integrated photomultiplier anode current is proportional to the number $\mathrm{N}$ of incident $\mathrm{K} \mathrm{X}$-ray quanta and their energy. $\mathrm{N}$ is in turn proportional to the ratio $\mathrm{i} / \mu$, where $\mathrm{i}$ means the saturation current of the ionisation chamber and $\mu$ the absorption coefficients in air of the the $\mathrm{K} \mathrm{X}$-rays energies. Finally, the normalized ratio F/i should coincide with the inverse of the absorption coefficients in air of all applied $\mathrm{K} X$-ray (figs 4 and 5 in reference [12]).

Further scintillation efficiencies plotted in fig. 1 are obtained from references [1315]. The common subject of these papers was the capture of orbital electrons by their nucleus, an alternative process to positron emission. Their aim was to determine electron capture ratios from different orbital shells, mainly $\mathrm{K} / \mathrm{L}$ and $\mathrm{L} / \mathrm{M}$. Electron captures are detected by measuring the emissions (characteristic X-rays, Auger electrons) caused by the subsequent rearrangements of the atomic shells. To avoid all corrections concerning $\mathrm{X}$-ray fluorescence yields or detection efficiencies of Auger electrons, the radioactive elements to be examined were incorporated in the $\mathrm{NaI}(\mathrm{Tl})$-lattice at convenient quantities during the growing process $[13,18]$. In this way, all radiations associated with the rearrangement of atomic shells after orbital electron capture in ${ }^{125} \mathrm{I}[13],{ }^{109} \mathrm{Cd}[14]$, and 202 $\mathrm{Tl}$ [15] were detected and produced the corresponding absorption edges $\# 1$. This internal source technique was only accepted for the determination of electron capture

\#1 $\mathrm{K}$ - and L-edge of Te (fig. 2 in reference [13]) in cascade with the ${ }^{125} \mathrm{I}-34.4 \mathrm{keV}$ emission of gammas or conversion electrons to the ${ }^{125} \mathrm{Te}$ ground state. $\mathrm{K}$ - and L-edge of $\mathrm{Ag}$ (fig. 3 in reference [14]) and the ${ }^{109 \mathrm{~m}} \mathrm{Ag}-87.7 \mathrm{keV}$ transition of gammas or conversion electrons. $\mathrm{K}-, \mathrm{L}-$, and $\mathrm{M}$-edge of $\mathrm{Hg}$ (figs 6 and 9 in reference [15]). 
ratios, if the observed absorption edges showed an exactly calibrated linear scintillation response, in order to be sure that all Auger emissions are correctly included. Elements which did not form mixed crystals with $\mathrm{NaI}(\mathrm{Tl})$, and therefore formed insensitive regions of a few micrometers around them, showed distorted emission spectra and were not accepted for the determination of capture ratios [18].

Another set of $\mathrm{NaI}(\mathrm{Tl})$-scintillation efficiencies, shown as the solid curve in fig. 1 , is obtained from the positron spectrum of the allowed ${ }^{22} \mathrm{Na}$ decay which was measured [16] in two different ways : with three differently sized NaI(Tl)-crystals (table 1 in reference [16]) containing ${ }^{22} \mathrm{Na}$ as a constituent of the crystal lattice, and with an iron-free short lens magnetic spectrometer (fig. 4 in reference [16]). Spectral distortions from the

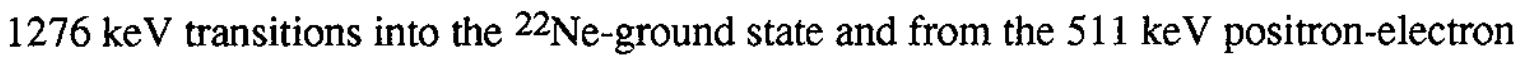
annihilations were avoided by coincidences between the ${ }^{22} \mathrm{NaI}(\mathrm{Tl})$-crystals and the $2298 \mathrm{keV}$ summing peak detected in large $\mathrm{NaI}(\mathrm{Tl})$-crystals $\$ 2$ surrounding them (fig. 2 in reference [16]). To avoid spectral distortions by positron scatterings inside the magnetic spectrometer, this was operated at three constant coil currents. The energy variations were achieved with different positron accelerations in a spherical condensor field by changing the $22 \mathrm{Na}$-source potential stepwise up to $\pm 100 \mathrm{kV}$. The spectra obtained with both methods (columns 8 and 9 of table 3 in reference [16]) were compared with the theoretical shape (column 7 of table 3 in reference [16]). The comparison with the crystal shaped curve (column 10 of table 3 in reference [16]), which agrees well with that of the magnet, is drawn in fig. 1.

Finally, fig. 1 also displays $\mathrm{NaI}(\mathrm{Tl})$-scintillation responses obtained from gamma sources located in crystal wells : spectra from a 202 Tl-source (fig. 11 in reference [15]) located at the bottom of the well $(2 \mathrm{~cm}$ diameter, $5 \mathrm{~cm}$ depth) in a $7.6 \mathrm{~cm}$ diameter and $7.6 \mathrm{~cm}$ high $\mathrm{NaI}(\mathrm{Tl})$-crystal ${ }^{\# 2}$ and from a $22 \mathrm{NaI}(\mathrm{Tl})$-crystal (fig. 3 in reference [16])

\footnotetext{
\#2 Harshaw Chemie, NV, De Meern, The Netherlands.
} 
placed in the well $(2.2 \mathrm{~cm}$ diameter, $5.1 \mathrm{~cm}$ depth) of a $10.2 \mathrm{~cm}$ diameter and $10.2 \mathrm{~cm}$ high $\mathrm{NaI}(\mathrm{Tl})$-crystal $\$ 2$. Again, the scintillation efficiencies are normalized to the averaged value of unity for each exposure.

\section{DISCUSSION}

\section{III-1 Excitation energies around the iodine absorption edges}

Inspecting fig. 1 it becomes obvious, that the scintillation efficiencies obtained from analysing references [12-16] do not confirm the non-linear responses reported in references $[3,5,7]$ for this energy region. Their pronounced structures around the iodine $\mathrm{K}-$ and L-absorption edges are also not present in the smooth response reported by B. D. Rooney and J. D. Valentine [17]. These structures are also contradicted by G. H. Narayan and J. Prescott [19] who have shown that these discontinuities on crossing the iodine Kedge are sensitive to the preparation of the crystal surface. C. G. Meggit [20] and R. Hill and A. J. L. Collinson [21] found similar evidence and the latter authors [22] have also shown that internal strain of $\mathrm{NaI}(\mathrm{Tl})$-crystals also affects their scintillation response.

The internal source technique, applied to determine capture ratios [13-15], was based on the complete detection of the short range Auger electrons. This has been therefore verified for each capture decay by careful energy calibrations around the relevant absorption edges including the nuclear transitions (gammas and conversion electrons) following the capture decay $[13,14]$.

\section{III-2 Dependance of scintillation efficiencies from excitation energies}

Several authors $[3,5,17]$ report an increase of $\mathrm{NaI}(\mathrm{Tl})$-scintillation efficiencies towards lower excitation energies. According to table 1, this is contradicted by references 
$[15,16]$. The efficiencies deduced from the shape factor of the ${ }^{22} \mathrm{Na}$-positron decay [16] are obtained with the internal source technique in coincidence with the summing peak $(2298 \mathrm{keV})$ of escaping annihilation- and gamma-quanta. This shape factor has been confirmed by measurements with a magnetic spectrometer [16] and by other authors (see reference [23]).

These efficiencies disagree with those recently obtained with Compton electrons $\left(\mathrm{h} v-\mathrm{h} \mathrm{v}^{\prime}=\mathrm{E}_{\mathrm{c}}\right.$ ) remaining in the $\mathrm{NaI}(\mathrm{Tl})$-crystal after coincidental detections of Compton scattered gammas $\left(h v^{\prime}\right)$ in a HPGe-detector [17], which yield efficiency increases up to $18 \%$ from $440 \mathrm{keV}$ to $10.8 \mathrm{keV}$. In this case, although information on the experimental set-up [17] is incomplete ${ }^{\# 3}$, there are a few points to stress :

i) pile-up arising from scintillations due to the source beam, scatterings from the collimators, environmental radiation, thermal noise of the NaI(Tl)-Photomultiplier cathode could distort the response of the system;

ii) systematic errors on the determination of $E_{c}$ caused by the finite collimation of $h v^{\prime}-$ quanta could lead to an underestimation of the $E_{c}$-values, due to the shape of the $\cos \theta-$ function $\# 4$;

iii) the ratio radiation/collision -loss amounts to $4.5 \%$ at $\mathrm{E}_{\mathrm{c}}=440 \mathrm{keV}$ [25] and becomes negligeable towards $100 \mathrm{keV}$, which could produce a positive correction of high $\mathrm{E}_{\mathrm{C}^{-}}$ scintillation efficiencies.

R. W. Peelle and T. A. Love [26] found $\sim 1 \%$ difference between the sum peak position of ${ }^{88} \mathrm{Y}(1.84 \mathrm{MeV}+0.899 \mathrm{MeV})$ and the ${ }^{24} \mathrm{Na}-2.754 \mathrm{MeV}$ gamma transition, and $\sim 2.5 \%$ difference between the ${ }^{207} \mathrm{Bi}$ sum peak $(1.063 \mathrm{MeV}+0.570 \mathrm{MeV})$ and the ${ }^{140} \mathrm{La}-1.596 \mathrm{MeV}$ gamma transition. Comparing in fig. 1 the efficiency values for the ${ }^{22} \mathrm{Na}-1.276 \mathrm{MeV}$ gamma transition with that of the annihilation sum peak (1.022 MeV)

\#3 Examples of missing information: dimensions of HPGe-detector, diameters and distances of collimators, ${ }^{137} \mathrm{Cs}$ source strength, energy threshold of $\mathrm{NaI}(\mathrm{Tl})$-PMT response, beam contamination due to collimator scatterings.

$\# 4 \underset{\mathrm{c} \Delta \mathrm{E}_{\mathrm{c}}}{+\Delta \mathrm{E}_{\mathrm{c}}}=\mathrm{h} v\left(1-\frac{1}{1+\frac{\mathrm{h} v}{511}(1-\cos (\theta \pm \Delta \theta))}\right)$ 
yields $\sim 2 \%$ difference, but opposite to the differences found by R. W. Peelle and T. A. Love. This difference lies within the error margins.

\section{III-3 Thallium concentrations in $\mathrm{NaI}(\mathrm{Tl})$-crystals}

R. Hill and A. J. L. Collinson [27] compared the scintillation efficiencies of $\mathrm{NaI}(\mathrm{Tl})$-crystals purchased from different manufacturers, who gave only estimates of their nominal Tl-concentrations. They found efficiencies (fig. 1a in ref. [27]) of up to $30 \%$ difference. They conclude that the density of Tl-luminescence centres is probably not proportional to the Tl-concentrations, except at low concentrations.

The NaI(Tl)-light yield reaches its best value above $0.05 \%$ molar Tl-concentration $(\sim 0.1$ weight $\% \mathrm{TII})$ in the grown ingot $[28,29]$ and remains constant up to at least $0.2 \%$ molar [29]. To guarantee constant light yield, $\mathrm{NaI}(\mathrm{Tl})$-ingots should therefore contain between 0.05 and $0.2 \%$ molar thallium increasing along their growing direction. These values might not always be met by the manufacturers, since it is extremely difficult to measure the $\mathrm{Tl}$-concentration inside a grown crystal ${ }^{\# 5}$. The $\mathrm{Tl}$-concentrations remaining in the grown ingots depend also strongly on the growing procedure applied (Bridgeman [30], Stockbarger [31], Czochralski [32]). For the internal source technique applied in references [13-16] a slightly modified Stockbarger method was used to grow the radioactive $\mathrm{NaI}(\mathrm{Tl})$-crystals. Their $\mathrm{Tl}$-concentration has been controlled [29] to meet the values $(0.05$ to $0.1 \%$ molar) for constant maximum light yield.

At 0.05 molar \% Tl-concentration the luminescence centres are distributed with an average distance of $5 \mathrm{~nm}$. Electrons of $1 \mathrm{keV}$ kinetic energy range nearly 10 times more. However, below $0.4 \mathrm{keV}$ electron energy, the ionisation loss becomes higher at the end of their range than the available Tl-concentration. Therefore, M. F. Mac Cann and K. M. Smith [33], who applied the internal source technique, found the Ne-K-edge $(0.865 \mathrm{keV})$

\#5 H. Klein [29] measured Tl-concentrations of about $40 \mathrm{NaI}(\mathrm{Tl})$-crystals containing between 0.002 and $0.2 \%$ molar $\mathrm{Tl}$-concentrations. They were determined via the counting rates of the ${ }^{204} \mathrm{Tl} \beta$-decay (internal source technique). The specific ${ }^{204} \mathrm{Tl}$-activity was determined with a methane-flow counter, in which the pulverized powder of the crystals was contained with a layer corresponding to the thickness of saturation for the ${ }^{204} \mathrm{Tl}$-betas. 
from the $22 \mathrm{Na}$-electron capture at $\sim 20 \%$ lower energy value compared with the correct position of the Ar-K-edge ( $3.2 \mathrm{keV})$ from the ${ }^{40} \mathrm{~K}$-electron capture.

\section{REFERENCES}

[1] P. Dorenbos, J. T. M. de Haas, and C. W. E. van Eijk, "Non-proportionality in the scintillation response and the energy resolution obtainable with scintillation crystals“, IEEE Trans. Nucl. Sci. , vol. 42, p. 2190, 1995.

[2] R. W. Pringle and S. Standil, "The gamma-rays from neutron-activated gold", Phys. Rev. , vol. 80, p. 762, 1950.

[3] D. Engelkemeir, "Non-linear response of $\mathrm{NaI}(\mathrm{Tl})$ to photons", Rev. Sci. Instr., vol. 27, p. $589,1956$.

[4] T. H. Jones, "The non-proportional response of NaI(T1)-crystals to diffracted Xrays", Nucl. Instr. and Meth., vol. 15, p. 55, 1962.

[5] W. Hink, "Das Ansprechvermögen eines NaI(Tl)-Szintillationskristalls im Energiebereich der K- und L-Absorptionskantes des Iods (33,2 bzw 5,2 keV) für Röntgenstrahlen", Z. Physik, vol. 169, p 370, 1962.

[6] F. T. Porter, M. S. Freedman, F. Wagner Jr., and I. S. Sherman, 'Response of $\mathrm{NaI}$, anthracene, and plastic scintillators to electrons and the problems of detecting low energy electrons with scintillation counters", Nucl. Instr. and Meth., vol. 39, p. 35, 1966. 
[7]

D. W. Aitken, B. L. Beron, G. Yenicay, and H. R. Zulliger, "The fluorescent response of $\mathrm{NaI}(\mathrm{Tl}), \mathrm{CsI}(\mathrm{Tl}), \mathrm{CsI}(\mathrm{Na})$, and $\mathrm{CaF}_{2}(\mathrm{Eu})$ to $\mathrm{X}$-rays and low energy gamma rays", IEEE Trans. Nucl. Sci. , vol. NS-14, p. 468, 1967.

[8] K. Brunner and W. Hink, "Die Impulshöhenverteilung und das Ansprechvermögen eines $\mathrm{NaI}(\mathrm{Tl})$-Szintillationsdetektors für monoenergetische Röntgenstrahlen im Energiegebiet einiger keV", Nucl. Instr. and Meth., vol. 82, p. $269,1970$.

[9] E. Sakai, "Recent measurements on scintillation-photodetector systems", IEEE Trans. Nucl. Sci. , vol. NS-34, p. 418, 1987.

[10] H. I. West, W. E. Meyerhof, ans R. Hofstadter, "Detection of X-rays by means of NaI(Tl) scintillation counters", Phys. Rev. , vol. 81, p. 141, 1951.

[11] C. J. Taylor, W. K. Jentschke, M. E. Remley, F. S. Eby, and P. G. Krüger, "Response of some scintillation crystals to charged particles", Phys. Rev. , vol. 84, p. 1034, 1951.

[12] S. Buhl, H. Leutz, and H. Muus, "Wellenlängenunabhängige Messung der Strahlungsleistung im Röntgengebiet mit einem NaI(Tl)-Szintillationszähler", Z. Physik, vol. 152, p. 272, 1958.

[13] H. Leutz and K. Ziegler, "The electron capture ratio in the decay of $\mathrm{I}^{125 " \text {, }}$ Nuclear Physics, vol. 50, p. 648, 1964. 
[14] H. Leutz, K. Schneckenberger, and H. Wenninger, "Electron capture ratios in $\mathrm{Cd}^{109}$ and internal conversion coefficients in Ag109m, Nuclear Physics, vol. 63, p. $263,1965$.

[15] H. Leutz, G. Schulz, and H. Wenninger, "Electron capture ratios in the decay of T1202", Nuclear Physics, vol. 75, p. 81, 1966.

[16] H. Wenninger, J. Stieve, and H. Leutz, "The Na 22 positron spectrum", Nuclear Physics, vol. A109, p. 561, 1968.

[17] B. D. Rooney and J. D. Valentine, "Benchmarking the Compton coincidence technique for measuring electron response non-proportionality in inorganic scintillators", IEEE Trans. Nucl. Sci. , vol. 43, p. 1271, 1996.

[18] G. Schulz, "On the solution of radioactive sources in NaI(T1) crystals", Nucl. Instr. and Meth., vol. 53, p. 320, 1967.

[19] N. R. Narayan and J. R. Prescott, 'Line-widths in NaI(Tl) scintillation counters for low energy gamma-rays", IEEE Trans. Nucl. Sci. , vol. NS-15, p. 132, 1968.

[20] G. C. Meggit, "The effect of crystal surface on the derived electron scintillation response of $\mathrm{NaI}(\mathrm{Tl}) "$, Nucl. Instr. and Meth., vol. 83, p. 313, 1970.

[21] R. Hill and A. J. L. Collinson, "Variation of resolution with gamma energy in activated alkali halide crystals", Proc. Phys. Soc., vol. 85, p. 1067, 1965. 
[22] R. Hill and A. J. L. Collinson, "The relationships between light output and energy resolution in thallium activated sodium iodide crystals", Nucl. Instr. and Meth., vol. 44, p. 245, 1966.

[23] H. Daniel, "Shapes of beta-spectra", Rev. Mod. Phys., vol. 40, p. 659, 1968.

[24] J. D. Valentine and B. D. Rooney, "Design of a Compton spectrometer experiment for studying scintillator non-linearity and intrinsic energy resolution", Nucl. Instr. and Meth., vol.A353, p. 37, 1994.

[25] M. J. Berger and S. M. Seltzer, "Tables of energy-losses and ranges of electrons and positrons", in Nuclear Series Report n³9, 1964, Editor: U. Fano.

[26] R. W. Peelle and T. A. Love, "Miethod for detecting non-proportionality of respons for gamma ray scintillators", Rev. Sci. Instr., vol. 31, p. 205, 1960.

[27] R. Hill and A. J. L. Collinson, "The effect on the scintillation efficiency of $\mathrm{NaI}(\mathrm{Tl})$ of changes in the thallium concentration and strain", Brit. J. Appl. Phys.,, vol. 17, p. 1377, 1966.

[28] I. A. Harshaw, H. C. Kremers, E. C. Stewart, E. K. Warburton, and I. O. Hay, U. S. At. Energy Comm., NYO-1577, 39, 1952.

[29] H. Klein, "Einban von Tl in NaI-Kristalle", Techn. Note Universität Heidelberg, 1964, unpublished.

[30] P.W. Bridgman, Proc. Amer. Acad. Abstr. Sci., vol. 58, p. 165, 1923. 
[31] D. C. Stockbarger, Rev. Sci. Instr., vol. 7, p. 133, 1936.

[32] J. Czochralski, Z. Phys. Chem., vol. 92, p. 219, 1918

[33] M. F. Cann and K. M. Smith, "On the detection of $1 \mathrm{keV}$ events in NaI(Tl)", Nucl. Instr. and Meth., vol. 65, p. 173, 1968. 
Table 1 : Averaged slopes (scintillation efficiencies per $\mathrm{MeV}$ ) taken from the indicated references. The negative sign means that the scintillation efficiency decreases with increasing energy.

\begin{tabular}{|l|c|c|c|}
\hline \multirow{2}{*}{ References } & Slope & \multicolumn{2}{|c|}{ Range } \\
& $\mathrm{MeV}^{-1}$ & $\mathrm{keV}$ & $\mathrm{keV}$ \\
\hline \hline Engelkemeir [3] & & & 400 \\
Aitken et al. [7] & -0.420 & 70 & 200 \\
\hline Rooney and Valenting & & & \\
\hline [17] & -0.760 & 20 & 420 \\
\hline 22Na (Beta) [16] & -0.046 & 40 & 512.5 \\
\hline 202Tl ext. [15] & 0.022 & 72.5 & 2298 \\
\hline 22 Na ext. [16] & 0.002 & 511 & \\
\hline
\end{tabular}




\section{FIGURE CAPTION}

Fig. 1: Light yield per unit excitation energy of electrons, X-rays or gammas. The individual points represent measurements with radioactive sources either dispersed throughout the $\mathrm{NaI}(\mathrm{Tl})$-lattice (marked int.) or placed inside the wells of $\mathrm{NaI}(\mathrm{Tl})$ crystals (marked ext.). The solid curve (marked ${ }^{22} \mathrm{Na}\left(\beta^{+}\right)$int.) is taken from the 22Na-positron spectrum. All these values yield a standard deviation $\sigma= \pm 0.9 \%$. 


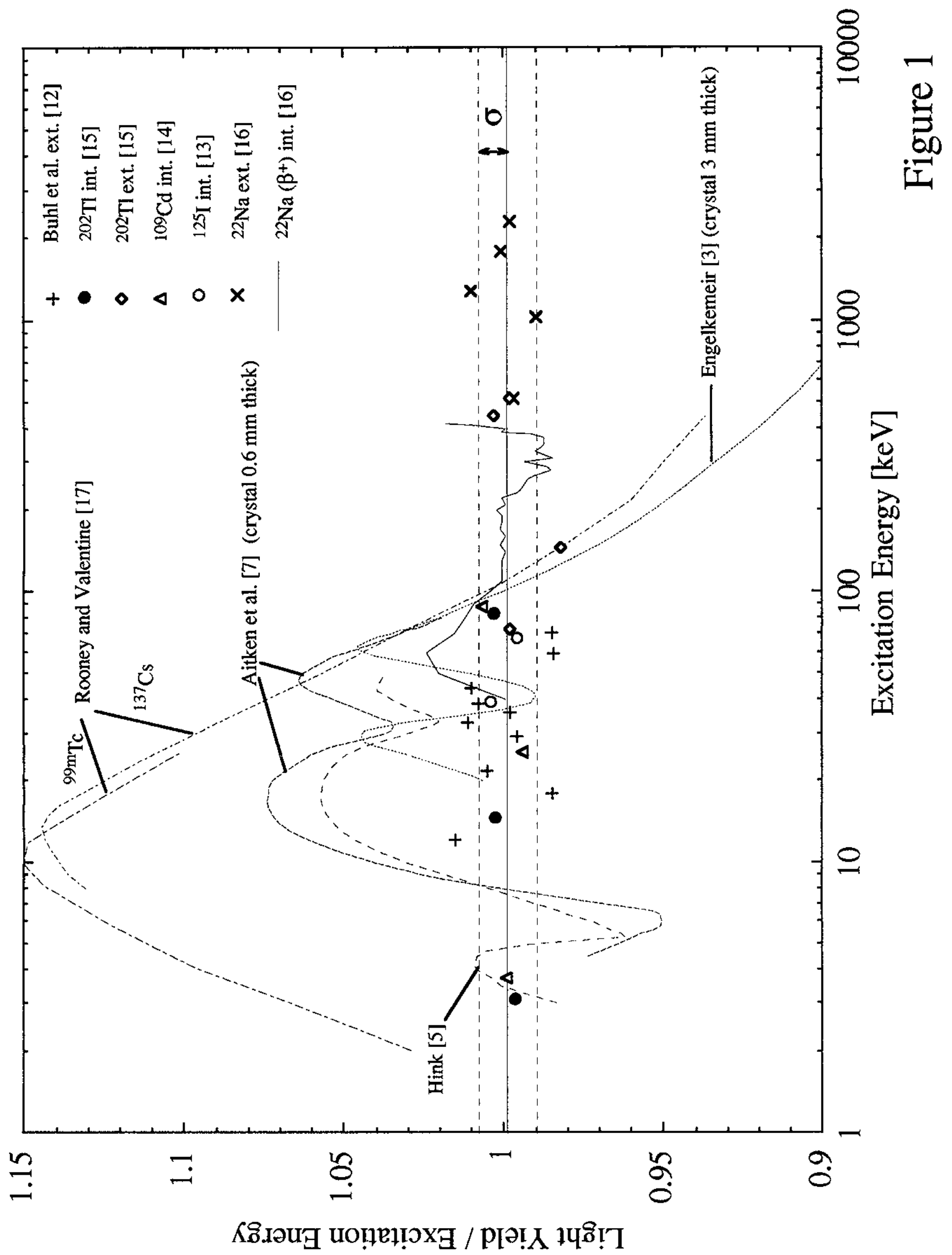

